\title{
THE IMPACT OF LOW INTENSITY SPECIFIC AND NONSPECIFIC STRENGTH-ENDURANCE TRAINING ON SUBMAXIMAL WORK CAPACITY IN TRAINED MALE ROWERS
}

\author{
Elar JaAkson, Jarek Mäestu \\ Institute of Sport Pedagogy and Coaching Sciences, \\ Faculty of Exercise and Sport Sciences, University of Tartu, Tartu, Estonia
}

\begin{abstract}
The aim of the current study was to compare the effects of general strength endurance and specific strength endurance training cycle to rowing performance in highly trained male rowers. Twelve international and national level male rowers ( $21.25 \pm 1.76$ years; height $188.3 \pm 4.92 \mathrm{~cm}$; body mass $84.07 \pm 5.61$ $\mathrm{kg}$; training experience $7.38 \pm 2.70$ years) took part in this investigation. The first group $(n=6)$ performed low intensity strength endurance trainings using rowing ergometer for specific exercises (Specific group; $S$ ), and the second group $(n=6)$ trained for strength endurance without rowing ergometer (Gym group; G). The experimental period lasted for four weeks. Stepwise incremental test was performed on the Concept II rowing ergometer (Morrisville, USA) before the first training week. After incremental ergometer test, subjects performed a constant $95 \%$ of Pa max test until exhaustion. This test was done 24 hours after incremental test and was performed before Week 1 and after Week 4 . The stroke rates of the $95 \%$ Pa max test were not significantly different ( $p>0.05$ ) between the two groups during both testing sessions. Despite the fact that both groups improved their $95 \% \mathrm{~Pa}$ max test results, no significant differences between the groups were found $(p>0.05)$. However, test result was significantly improved only in G group (from $362 \pm 108$ to $416.5 \pm 133 \mathrm{~s}$ ), while no significant changes were observed in $95 \% \mathrm{~Pa}$ max test result in $\mathrm{S}$ group (from $372.8 \pm 132.3$ to $442.3 \pm 153.1 \mathrm{~s}$ ). No other significant differences were observed either between the two groups or between the two testing sessions $(p>0.05)$. In conclusion, a 4 week non-specific strength endurance training program has an advantage over the specific strength endurance training on rowing ergometer in developing aerobic capacity in male rowers.
\end{abstract}

Keywords: strength endurance, rowing, aerobic performance, strength training 


\section{INTRODUCTION}

Rowing is a strength endurance type of sport where aerobic and strength capacities play an important role in achieving a maximal result on the classical 2000 meter distance. This might cause timing problems, since not all capacities can be developed simultaneously [19]. For rowers it is very important to include strength endurance trainings in addition to aerobic trainings into annual training plan [3]. During the preparatory period, that usually starts in November, the total amount of aerobic trainings can vary from approximately $90 \%$ of the whole training time $[7,17]$ to $99 \%$ of the total training volume [13]. During endurance workout muscles do thousands of contractions at relatively low contraction force, while during strength and power training only few contractions at very high intensity are done. Therefore, those two concepts cannot be trained simultaneously. Moreover, the influence of maximal strength and power training is mainly on fast twitch fibres, while the effect of strength endurance training is mainly on slow twitch fibres [3].

It has also been argued that if the performance of the athlete increases, more time should be devoted to specific training in comparison with general training $[8,15]$. Boland and Hosea $[6]$ have also argued that strength training should be focused as close as possible to the movements a rower does in the boat. Strength endurance at low speeds should have the main effect on slow-twitch muscle fibres, while strength and power training focus on fast-twitch fibres [19]. However, it has been found that power training at low resistance causes lactate concentration to raise $5.00 \pm 1.2 \mathrm{mmol} / \mathrm{L}$, while power training at high resistance causes lactate to rise to $6.35 \pm 1.7 \mathrm{mmol} / \mathrm{L}$ [19]. However, there are no data in the literature that have studied the training effect of low intensity, high volume strength endurance training to rowing performance, while lots of data exists on the development and maintaining of strength capacities. For example, Bell et al. [1] have investigated whether strength training at high or low speeds has the influence on anaerobic power and maximal strength. The first group in that study did power exercises at $40 \% \mathrm{RM}$ and $18-22$ reps, the second group did 6-8 sets of maximal strength at low speeds and the third group did only endurance training at low intensity. The results showed that the only group that improved performance was the endurance training group. However, no data exists in the literature of the effect of a strength endurance training cycle to rowing performance.

The aim of the current study was to compare the effects of the general strength endurance and specific strength endurance training cycle to rowing performance in highly trained male rowers. 


\section{MATERIALS AND METHODS}

\section{Subjects}

Twelve international and national male rowers $(21.25 \pm 1.76$ years; height $188.3 \pm 4.92 \mathrm{~cm}$; body mass $84.07 \pm 5.61 \mathrm{~kg}$; training experience $7.38 \pm 2.70$ years) took part in this investigation (Table 1). Subjects were healthy and were not taking any medicine during the study period. All subjects were informed about the study procedures before signing a written informed consent to participate in the study.

\section{Procedures}

The investigation took part at the beginning of the preparatory period (i.e. from the end of October) and lasted for four weeks. This training period can be characterized as a period of low intensity and high volume, with most of the trainings done below aerobic threshold. The subjects were divided into two groups using matched pair design. The first group $(n=6)$ performed low intensity strength endurance trainings using rowing ergometer for specific exercises (Specific group; $S$ ), and the second group $(n=6)$ trained for strength endurance without rowing ergometer (Gym group; $G$ ). The used exercises were with similar volume and intensity for both groups, however in $S$ group rowing ergometer was used for leg press, arm pull, snatch, power clean, etc. Training volume during the first week (Week1) was $593.3 \pm 5.66 \mathrm{~min}$, for the second week (Week2) 630.7 $\pm 5.61 \mathrm{~min}$, for the third week (Week 3) 670.4 $\pm 6.12 \mathrm{~min}$ and for the fourth week (Week 4) 586.6 $\pm 7.46 \mathrm{~min}$ in both groups. Additionally, both groups trained about $8 \%$ of the whole training time in single sculls, $22 \%$ of the training time was biking or running, and approximately $30 \%$ of the whole training time were strength endurance trainings, with $40 \% 1 \mathrm{RM}$ at 17 times per minute rate. Athletes trained 7 times per week, with one day of full rest.

Table 1. Anthropometrical and physiological parameters (mean \pm SD) of the subjects according to the study group

\begin{tabular}{lcc}
\hline Parameter & S group & G group \\
\hline Height $(\mathrm{cm})$ & $185.5 \pm 3.3$ & $191.1 \pm 4.7^{\star}$ \\
\hline Body mass $(\mathrm{kg})$ & $82.7 \pm 6.8$ & $85.3 \pm 4.3$ \\
\hline Training experience (years) & $7.5 \pm 3.0$ & $7.3 \pm 2.6$ \\
\hline $\mathrm{VO}_{2 \max }(\mathrm{L} / \mathrm{min})$ & $5.1 \pm 0.58$ & $5.5 \pm 0.33$ \\
\hline $\mathrm{VO}_{2 \max }(\mathrm{w})$ & $348 \pm 38.1$ & $367 \pm 33.6$ \\
\hline
\end{tabular}

Note: $\mathrm{S}$ - specific training group, $\mathrm{G}$ - general training group, *significantly different from $S$ group, $\mathrm{p}<0.05$ 


\section{Incremental test on rowing ergometer}

Stepwise incremental test was performed on the Concept II rowing ergometer (Morrisville, USA) before the first training week. The subjects were asked not to participate in any physical activity exercises during the previous 24 hours preceding the test. The test started at $150 \mathrm{~W}$ and was increased after every three minutes by $50 \mathrm{~W}$ until volitional exhaustion. Heart rate (HR) was measured continuously throughout the test using a commercially available HR monitor (Polar S725X, Polar Electro, Finland). During the test maximal oxygen consumption and the corresponding power (maximal aerobic power; Pa max) were calculated. The following formula was used to calculate Pa max:

$$
\mathrm{Pa} \max =\mathrm{P} 1+\mathrm{P} 2 \times \mathrm{T} / 180 \text {, where: }
$$

P1 was the load that was previous to the load, where maximal oxygen consumption occurred. In case maximal oxygen consumption occurred at the end of the stage, then Pa max equalled the power of the stage; P2 was the increase of the load ( $50 \mathrm{~W})$; and $\mathrm{T}$ was the time in seconds of the last stage.

\section{Submaximal intensity tests}

After incremental ergometer test, subjects performed a constant $95 \%$ of Pa max test until exhaustion. This test was done 24 hours after incremental test and was also performed before Week 1 and after Week 4 . The subjects were not allowed to any moderate or vigorous activity 24 hours before the test. Both continuous intensity tests were held between 10-12 am and testing time was kept constant for each subject. A standardized warm-up at the intensity of 50\% Pa max for 20 minutes was performed. To increase the objectivity of the tests, the subjects did not see the time nor stroke rate from ergometer display. However, they were verbally encouraged to achieve maximal result. During the test time, average power, covered distance and average stroke rate were registered.

\section{Statistical analysis}

A statistical package SPSS for Windows was used. Descriptive parameters (mean \pm SD) were calculated. The differences between the variables were calculated using paired-T tests, as data was normally distributed. The statistical significance was set at $(\mathrm{p}<0.05)$. 


\section{RESULTS}

Changes in training volume during the four week period increased significantly during Week 2 and 3 and then decreased significantly during Week 4 (Figure 1).

Descriptive parameters of the incremental test, maximal aerobic power and anaerobic threshold indices are presented in Table 2. No significant differences between the parameters were seen between the two studied groups, except the height of the G group was significantly lower $(191.1 \pm 4.7$ and $185.5 \pm 3.4$ for $S$ and G groups, respectively).

Table 2. The results of the incremental rowing ergometer test (mean \pm SD) of the subjects according to the study group

\begin{tabular}{lccc}
\hline Parameter & Total & S & G \\
\hline $\mathrm{VO}_{2 \max }(\mathrm{L} / \mathrm{min})$ & $5.32 \pm 0.50$ & $5.13 \pm 0.58$ & $5.5 \pm 0.33$ \\
\hline $\mathrm{VO}_{2 / \mathrm{kg}}(\mathrm{mL} / \mathrm{min} / \mathrm{kg})$ & $62.8 \pm 6.94$ & $62.3 \pm 8.66$ & $63.2 \pm 5.53$ \\
\hline $\mathrm{P}_{\max }(\mathrm{w})$ & $376.7 \pm 25.34$ & $373.3 \pm 16.33$ & $380 \pm 33.46$ \\
\hline $\mathrm{Pa}_{\max }(\mathrm{w})$ & $357.6 \pm 35.32$ & $348.7 \pm 38.18$ & $366.5 \pm 33.2$ \\
\hline $\mathrm{V}_{\mathrm{E}}(\mathrm{L} / \mathrm{min})$ & $188.8 \pm 21.75$ & $182.1 \pm 25.69$ & $195.4 \pm 16.58$ \\
\hline
\end{tabular}

Note: $\mathrm{S}$ - specific training group, $\mathrm{G}$ - general training group

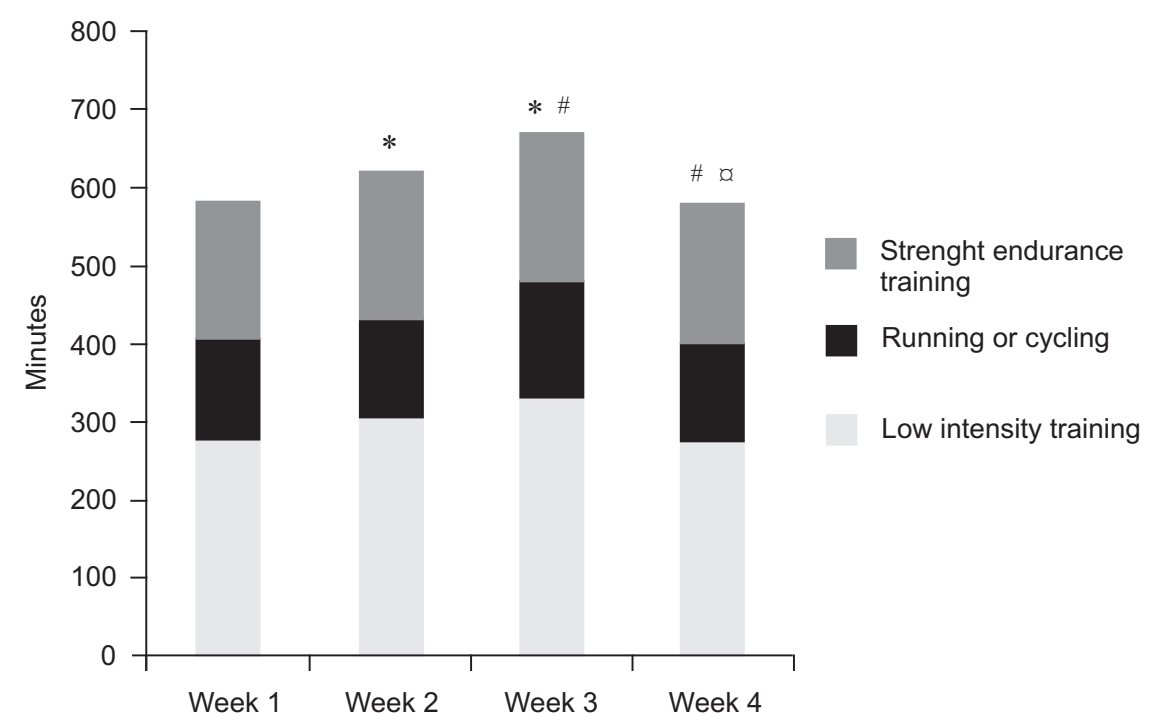

Figure 1. Training volumes during the 4 week study period in both groups. *significantly different from week 1 , "significantly different from week 2 , " significantly different from week 3 . 
Stroke rates during the $95 \% \mathrm{~Pa}$ max test were not significantly different $(\mathrm{p}<0.05)$ between the two groups during both testing sessions (Table 3$).$ Despite the fact that both groups significantly improved their $95 \% \mathrm{~Pa}$ max test result, no significant differences in performance between the groups were found ( $\mathrm{p}>0.05$ ). However, $95 \%$ Pa max test result was significantly improved only in G group (from $362 \pm 108$ to $416.5 \pm 133 \mathrm{~s}$ ), while no significant changes were observed in 95\% Pa max test result in S group (from $372.8 \pm 132.3$ to $442.3 \pm 153.1 \mathrm{~s})$. No other significant differences were observed either between the two groups or between the two testing sessions ( $p>0.05)$.

Table 3. The results of the $95 \% \mathrm{~Pa}_{\max }$ test according to the study group

\begin{tabular}{lcccc}
\hline Parameter & $\begin{array}{c}\text { S before } \\
\text { 4 weeks }\end{array}$ & $\begin{array}{c}\text { S after } \\
\text { 4 weeks }\end{array}$ & $\begin{array}{c}\text { G before } \\
\text { 4 weeks }\end{array}$ & $\begin{array}{c}\text { G after } \\
\text { 4 weeks }\end{array}$ \\
\hline Distance $(\mathrm{m})$ & $1815 \pm 627$ & $2150 \pm 698$ & $1752 \pm 512.9$ & $2060 \pm 620.8^{*}$ \\
\hline Time $(\mathrm{sec})$ & $372.8 \pm 132.3$ & $442.3 \pm 153.1$ & $362 \pm 108$ & $416.5 \pm 133.7^{*}$ \\
\hline Stroke rate $(\mathrm{s} / \mathrm{m})$ & $30.8 \pm 1.7$ & $29.5 \pm 1.5$ & $30 \pm 1.6$ & $29.33 \pm 1.96$ \\
\hline Average power $(\mathrm{W})$ & $332.3 \pm 38.4$ & $332.3 \pm 35.8$ & $345.83 \pm 31.6$ & $346.6 \pm 30.5$ \\
\hline
\end{tabular}

Note: $\mathrm{S}$ - specific training group, $\mathrm{G}$ - general training group. *Significantly different from before 4 week training period $(p<0.05)$

\section{DISCUSSION}

The main result of the present study was that strength endurance trainings in the gym have significantly higher impact to submaximal rowing capacity (95\% of maximal aerobic power) compared to strength endurance trainings performed on the rowing ergometer.

The aerobic energy source is approximately $70-80 \%$ of the total energy needed during the $2000 \mathrm{~m}$ rowing race $[10,11]$. Therefore, low intensity aerobic trainings below aerobic threshold and strength endurance trainings are for the basis of the preparatory phase of the rowers [19]. A very important aspect is the intensity of the training to ensure an adaptation from one side and to prevent athletes from overtraining from the other side [16]. In the current study the used training cycle was designed to develop a strength endurance with similar training loads that were used before in the literature $[1,3,4]$, being however lower than the loads that have been found to be relatively stressful and might lead to excessive fatigue $[15,18]$. Therefore, we did not intend to use too high increases in training volume that could have negative influence on performance. For example, Lehmann et al. [12] have found that sudden increases in training volume might result in higher fatigue compared to increases in training 
intensity. Similarly, Rämson et al. [18] have found that increases in training volume for $50 \%$ during 4 weeks resulted in decreases in aerobic performance.

The results of our study indicate that low intensity trainings to develop strength endurance in gym resulted in significant increase of the 95\% Pa max performance, while similar trainings using high resistance exercises on rowing ergometer resulted in no change in aerobic performance. Previous studies [3, 19] indicated that low intensity resistance trainings have negative influence on rowing performance compared to specific high tempo trainings. These discrepancies might be explained by the use of different performance test. In the current study, the performance test had mainly aerobic component, while Steinacker et al. [19] used maximal performance test, where a significant amount of energy comes from anaerobic sources. The intensity of the current test was chosen because during maximal tests, the result of the test depends highly on the motivation of the athlete $[9,14]$ and therefore the test result can be more easily manipulated. Using a fixed test load on the other side allows the athletes to perform at similar intensities. However, the negative aspect of constant load test is its weak similarity to real-life performance. According to the literature we can, however, conclude that $95 \%$ Pa max test is very highly related to 2000 meter rowing ergometer performance $[11,20]$.

The hypothesis of the current study was that specific rowing ergometer is more advantageous in order to improve $95 \% \mathrm{~Pa}$ max performance in male rowers, as the nature of the movements, muscle contractions and coordination are more similar to rowing compared to strength exercises in the gym that the other group used. Some authors have argued that strength endurance exercises did not change significantly power and changes in performance are rather the result of the specific endurance trainings $[1,2,19]$. In our study we found significant changes in the covered distance $(\mathrm{p}<0.05)$ and performance time in $95 \%$ Pamax test, while no changes were observed in stroke rate and average power (see Table 3).

The non-significant improvement in $S$ training group might be caused by the exercises used as there was no previous experience in designing strength endurance training program on a rowing ergometer. Furthermore, to our best knowledge no references in the literature are currently available. One possible cofounder might have been a relatively high overall performance level of the subjects and because of that, a 4-week training cycle might have been too short to detect significant changes in performance. Another limitation might also be that training loads were not individually manipulated, but were similar to all the athletes in the group. However, at least two of the subjects complained for higher feelings of fatigue after the 4-week training program. Bell et al. [3] have found that general strength parameters can be maintained if at least two 
strength trainings per week are performed in addition to aerobic trainings. Therefore, the amount of the three strength endurance sessions per week would have been also higher in order to stimulate adaptive processes more effectively. For example, Bell et al. [1] found significant changes in endurance trained group after 5 weeks of trainings. However, the studies of Bell et al. $[1,3,4]$ did not give any indication of the used training loads, but rather the used training cycles.

It has also been found previously that rowers should decrease low tempo strength endurance trainings and increase high speed power trainings during off season period [9]. During this period it is of importance to use exercises that are close to the specific movements in the boat (i.e. using the same tempo and intensity). Contrary, it has also been found that low tempo strength endurance trainings helps to increase the power during the first phase of the rowing stroke [4]. Additionally, low intensity strength endurance trainings will not cause accumulation of waste products like lactate and carbon dioxide [5] in the organism that in long term can lead to sympathetic stress.

In conclusion, a 4-week non-specific strength endurance training program has an advantage over the specific strength endurance training on rowing ergometer in developing aerobic capacity in male rowers.

\section{REFERENCES}

1. Bell G, Petersen SR, Quinney HA, Wenger HA. (1989) The effect of velocityspecific strength training on peak torque and anaerobic rowing power. J Sports Sci, 7: 205-214

2. Bell G, Petersen S, Wessel J, Bagnall K, Quinney HA. (1991) Physiological adaptions to concurrent endurance training and low velocity resistance training. Int $\mathrm{J}$ Sports Med, 12: 384-390

3. Bell GJ, Syrotuik DG, Attwood K, Quinney HA. (1993) Maintenance of strength gains while performing endurance training in oarsmen. Can J Appl Physiol, 1993, 18: 104-115.

4. Bell G, Attwood K, Syrotuik D, Quinney HA. (1997) Comparison of the physiological adaptions to high vs. low stroke rate training in rowers. Sport Med Train Rehabil, 8: 113-122

5. Bishop D, Jenkins DG, Mackinnon LT. (1998) The relationship between plasma lactate parameters, $\mathrm{W}_{\text {peak }}$ and 1-h cycling performance in women. Med Sci Sports Exerc, 30: 1270-1275

6. Boland AL, Hosea TM. (1991) Rowing and sculling in the older athlete. Clin Sports Med, 10: 245-256

7. Fiskerstrand A, Seiler K. (2004) Training and performance characteristics among Norwegian international rowers 1970-2001. Scand J Med Sci Sports, 14: 303-310 
8. Hagerman FC, Staron RS, Murray TF, Hikida RS, Grant S. (1992) A comparison of the effects of traditional and non-traditional resistance training programs on rowing performance and muscle metabolism. Sport Medicine Symposium, USRA Los Angeles

9. Hagerman FC. (2000) Physiology of competitive rowing. In Garrett WE Jr, Kirkendall DT (eds). Exerc Sport Sci, 843-872

10. Ingham S, Carter H, Whyte GP, Doust JH. (2008) Physiological and Performance Effects of Low- versus Mixed-Intensity Rowing Training. Med Sci Sports Exerc, 40: 579-584

11. Jürimäe J, Mäestu J, Jürimäe T, Pihl E. (2000) Prediction of rowing performance on single sculls from metabolic and anthropometric variables. J Hum Mov Sci, 38: $123-136$

12. Lehmann M, Wieland H, Gastmann U. (1997) Influence of an unaccustomed increase in training volume vs intensity on performance, hematological and bloodchemical parameters in distance runners. J Sports Med Phys Fitness, 37: 110-116

13. McNeely, E. (2005) Designing your training plan. Rowing Faster. Champaign: Human Kinetics, 99-110

14. McConnell AK, Romer LM. (2004) Respiratory muscle training in healthy humans: resolving the controversy. Int J Sports Med, 25: 284-293

15. Mäestu J, Jürimäe J, Jürimäe T. (2003) Hormonal reactions during heavy training stress and following tapering in highly trained male rowers. Horm Metab Res, 35: 109-113

16. Mäestu J, Jürimäe J, Jürimäe T. (2005) Monitoring performance and training in rowing. Int J Sports Med, 35: 597-617

17. Nielsen T, Daigneault T, Smith M. (2002) Intermediate rowing methodology. FISA, Lausanne, 68-76

18. Rämson R, Jürimae J, Jürimae T, Mäestu J. (2008) The influence of increased training volume on cytokines and ghrelin concentration in college level male rowers. Eur J Appl Physiol, 104: 839-846

19. Steinacker JM, Lormes W, Lehmann M, Altenburg D. (1998) Training of rowers before World Championships. Med Sai Sports Exerc, 30: 1158-1163

20. Weston A, Myburgh K, Lindsay F, Dennis S, Noakes T, Hawley J. (1997) Skeletal muscle buffering capacity and endurance performance after high intensity training by well-trained cyclists. Eur J Appl Physiol, 75: 7-13

\section{Correspondence to:}

Jarek Mäestu

Institute of Sport Pedagogy and Coaching

Faculty of Exercise and Sport Sciences

University of Tartu

Ravila 14a, 50411 Tartu

Estonia

E-mail: jarek.maestu@ut.ee 